\title{
Reflex sympathetic dystrophy syndrome associated with burns of the upper extremity
}

\author{
Chenicheri Balakrishnan MD, Lisa M Bradt RN, David Rankin MD, Thomas A Pane MD
}

\begin{abstract}
C Balakrishnan, LM Bradt, D Rankin, TA Pane. Reflex sympathetic dystrophy syndrome associated with burns of the upper extremity. Can J Plast Surg 2004;12(1):37-38.

Reflex sympathetic dystrophy syndrome is an ill-defined symptom complex with clinical manifestations of excessive pain, joint stiffness and soft tissue changes. It rarely manifests following burns. Diagnosis is usually made from clinical symptoms and ganglion block. Early diagnosis and institution of conservative management is required to control symptoms and disability.
\end{abstract}

\begin{abstract}
Syndrome de dystrophie sympathique réflexe associé à des brûlures aux membres supérieurs

Le syndrome de dystrophie sympathique réflexe forme un tableau clinique complexe encore mal défini qui s'accompagne de manifestations de douleur intense, de raideur articulaire et d'anomalies des tissus mous. Il apparaît rarement après des brûlures. Le diagnostic se fonde en général sur les symptômes cliniques et la ganglioplégie. Il faut sans tarder poser le diagnostic et instaurer un traitement conservateur pour maîtriser les symptômes et prévenir les incapacités.
\end{abstract}

Key Words: Reflex sympathetic dystrophy in burns

$\mathbf{R}$ eflex sympathetic dystrophy syndrome is an unusual sympRtom complex characterized by clinical features of excessive pain, joint stiffness and soft tissue changes causing considerable disability. These may occur even following minor injury or surgery to the extremity. It is a major cause of disability and pain to the patient and of great concern to the caregiver. Sudeck (1) was the first to describe these symptoms as an exaggerated inflammatory response to injury. Despite advances in nosology, etiology, pathogenesis and treatment, reflex sympathetic dystrophy remains ill defined.

\section{MATERIALS AND METHODS}

Patients admitted to a burn unit with partial thickness burns to the extremity were followed to determine the incidence, clinical course and results of management of reflex sympathetic dystrophy. The diagnosis of reflex sympathetic dystrophy was made from clinical symptoms and signs and confirmed using stellate ganglion block. The clinical manifestation included excessive pain of the extremity, stiffness affecting even the uninjured joints of the extremity, swelling, erythema and trophic changes.

\section{RESULTS}

During a five-year period, four patients were noted to have signs and symptoms suggestive of reflex sympathetic dystrophy. These four patients form less than $1 \%$ of the patients treated in the unit. There were three men and one woman in this group, with the ages ranging from 28 to 52 years. Etiology of the thermal injury was flame burns in three patients and grease burns in the other. One patient sustained his injury at work.

Although in all of these four patients the wounds healed and the patients regained almost full function of the affected extremity, the symptoms and signs suggestive of reflex sympathetic dystrophy appeared approximately eight to 10 weeks after the injury. The symptoms were described as a burning pain similar to the pain of the initial burn. The affected extremity was swollen, warm and erythematous. Passive movements of the extremity were painful. The grip strength was diminished and these patients were unable to tolerate any pressure over the extremity. Electromyography and nerve conduction studies showed no evidence of polyneuropathy or entrapment neuropathy. Management of these patients involved using a protocol addressing reduction of edema, pain management, and active and passive range of motion of the joints as tolerated by patient. Retrograde massage, elevation and gentle range of movements were used to reduce edema. Pain management was accomplished by the use of high or low rates of transcutaneous electrical nerve stimulation, massages, manual desensitization exercises and pharmacological manipulations. All patients had dramatic relief from stellate ganglion blockade.

\section{DISCUSSION}

Reflex sympathetic dystrophy syndrome, although first described over a century ago, remains poorly understood and often unrecognized. The pathogenesis has been linked to an abnormal sympathetic nervous reflex. Physiological studies using oscillography, plethesmography, skin temperature measurement and venous blood gas determinations have suggested an increase in blood flow and venous oxygen saturation of the affected extremity. Hence, the clinical manifestation of the disease may be due to local sympathetic nervous system overactivity. Various clinical types of reflex sympathetic dystrophy syndromes have been suggested, namely, minor and major dystrophy and shoulder hand syndromes. The reported incidence 
of reflex sympathetic dystrophy is $1 \%$ to $2 \%$ following various fractures and $2 \%$ to $3 \%$ after peripheral nerve injury. The incidence is higher with fractures of the wrist.

During the early phase of the disease, the affected extremity is swollen; the skin is erythematous and feels warm to touch. Joint movements of the extremity may be painful. These signs and symptoms resemble that of a superficial partial thickness burn. Clinically, the periarticular areas are most affected by the disease process. Although there is prominent involvement of the periarticular regions, associated radiological evidence of severe patchy osteoporosis is frequently seen in the involved extremity. Reflex sympathetic dystrophy of both patellae has been reported following burns of both knees (2). Most of the previously reported cases of reflex sympathetic dystrophy involved male patients (2,3). According to these reports, the symptoms of reflex sympathetic dystrophy in this rare complication of burn injury to the extremity were persistence or reappearance of acute burn symptoms. In our series, a female patient developed her symptoms following partial thickness burns to her face and hands from a house fire. The earliest symptom in our group of patients was intolerance to pressure.

Conservative management of these patients, using the modalities to reduce edema, pain and hypersensitivity including stellate ganglion blocks, produced good symptomatic relief and good range of motion. Although reflex sympathetic dystrophy is a rare syndrome following burns, early recognition and management will decrease pain and suffering for the patient.

\section{REFERENCES}

1. Sudeck P. Die sogenannte akute knochenatrophie als entzundungsvorgang. Chirurg 1942;15:449-58.

2. van der Lann L, Goris RJA. Reflex sympathetic dystrophy after a burn injury. Burns 1996;22:303-6.

3. Isakov E, Boduragin N, Korzets A, Susak Z. Reflex sympathetic dystrophy of both patellae following burns. Burns 1995;21:616-8. 